\title{
See it my way: Using patient, family/carer and staff stories to inspire and motivate NHS staff
} Health Design

\section{DESIGN}

INSIGHT

\author{
Theresa Hegarty
}

Royal United Hospitals Bath NHS Foundation Trust, Combe Park, Bath, United Kingdom

To Cite: Hegarty T. See it my way: Using patient, family/carer and staff stories to motivate NHS staff. JHD. 2018;3(4):150-153.

https://doi.org/10.21853/JHD.2018.67

\section{Corresponding Author:}

Theresa Hegarty

Royal United Hospitals Bath NHS Foundation Trust

Combe Park, Bath, United Kingdom

BA1 3NG

theresa.hegarty@nhs.net

@ 2018 The Authors. Published by Archetype Health

Pty Ltd.. This is an open access article under the CC BY-NC-ND 4.0 license.

\section{SUMMARY}

The See it my way (SIMW) model developed in 2010 is a free, onsite, quarterly storytelling event for patients, carers, and staff that lasts for one hour. Patients share their stories of living with a health condition and their care experiences; carers share their stories as participants in the health journey; and staff share their stories as providers of care. The SIMW model has been used widely in the Royal United Hospitals Bath NHS Foundation Trust since 2010. SIMW events actively promote the voices of people who are not normally heard. The SIMW model increases empathy, compassion, and kindness across all staff roles, and helps staff develop listening skills and reflective practice.

\section{Key Words}

Patient-centred care; empathy; patient engagement; healthcare staff; staff-patient interactions

\section{INTRODUCTION}

Over a decade ago, staff within the United Kingdom's National Health Service (NHS) determined that information gathered from patients and their caregivers could be used to improve the quality of healthcare. Efforts were undertaken to determine the best way to capture the experiences of patients and carers. The See it my way (SIMW) model, developed in 2010, was part of the movement to focus on stories and experience. Since then, across the NHS, it has become established practice that staff listen to patient and carer stories. Staff then use the stories to connect with service user experience and make improvements. These personal stories include the sharing of personal feelings and emotions arising from having poor health, living with a health condition and the experience of being treated within the NHS. There is evidence that the debriefing process of assembling and assimilating experience is an important component of health and wellbeing.

\section{SUMMARY}

In 2010, the concept of See it my way events was created and led by the author, Theresa Hegarty, then Head of Patient Experience at Royal United Hospitals (RUH) Bath NHS Foundation Trust. SIMW is a free, onsite, quarterly storytelling event for patients, carers, and staff that lasts for one hour. It is a time to listen to the stories of patients and family/carers about living with a situation or condition and their experiences within the healthcare organisation, a reflective session to connect with the person behind the condition. A staff story is included to emphasise a communal aspect that values the humanity of every person within the hospital.

\section{LESSONS LEARNED}

The SIMW model enables staff to have a deeper understanding of patient, carer, and staff experiences. Events actively promote the voices of people who are not normally heard or given a platform. Real-life stories shared by patients inspire staff and increase empathy, compassion, and kindness across all staff roles, and help staff develop listening skills and reflective practice. The SIMW model was partly designed in light of evidence that moving towards a person-centred approach improves staff-patient interactions in areas such as medication activities ${ }^{1}$ and bridges the gap between healthcare, professional, and patient/family views of family-centred care. ${ }^{2}$

There are numerous examples of staff gaining a deeper understanding of patient and carer experience from the stories told at SIMW. Since 2010, staff have been providing feedback after each event and their feedback has been recorded and reported in RUH Patient Experience Board Reports. ${ }^{3,4}$ Several examples of participant feedback on how the stories 
have increased understanding include:

"Amazing way to connect people as uses our human interest in stories."

"Bravery of speakers to narrate what has happened-best thing I had done all year-exceptional."

"There wasn't a dry eye in the house."

"Very moving, also interesting as gives better perspective of patient conditions and how things affect them."

"More powerful than collecting questionnaire data, as people are more able to tell you what you would not ask on a questionnaire."

"I love the interconnectedness of the speakers, I learn so much about the speakers' conditions, by the end of it, it's really changed me."

"Reminder of why we do our jobs and how to do them to the best of our abilities."

"Space to re-humanise, brings you back to why you chose your job and what kind of clinician you want to be."

"With a whole ward of patients, it's hard to focus on individuals' stories as one is task driven, we're rushed off our feet-SIMW was a luxury to sit down and think about what it must be like for the patient."

"SIMW is vital to re-boot us emotionally and it also gives us useful things we can say in certain situations, by role modelling useful phrases."

"Real life-stories remind us that things happen to individuals, and stop over generalisation of patient experiences, hence generate more in-depth understanding and compassion for what people are going through."

Regarding staff experience, the SIMW model has several proven benefits:

1. It shows that listening to staff stories and their experiences working with people with certain conditions can inspire and motivate.

2. It raises awareness about the skills and knowledge of staff who focus on a specific condition or area.

3. It informs and engages staff about current clinical and practical work at an organisation.

4. It can help recruit staff to support current projects that improve the patient experience.

Because, like Schwartz Rounds, the emphasis of the SIMW model is on listening and empathy and not on action planning and results. Thus far, we have not kept systematic records of staff getting involved with Quality Improvement projects, though this could be developed in future.

The SIMW model and practice has been tried and tested in the RUH NHS Trust since 2010 and continues to take place as a popular and successful quarterly event under the leadership of Sharon Manhi, Lead for Patient and Carer Experience. National interest in the model continues. The inclusive approach involved with SIMW complements the Schwartz Round model, ${ }^{5}$ which does not include patients and families/carers.

Several staff from other NHS trusts have attended SIMW events at RUH, and information has been shared; however, to date there is no significant evidence that this approach has resulted in a sustained programme at any other organisation. Nevertheless, the author has developed and trialled a national training programme. What is required now is a training programme in partnership with the RUH Trust that provides training and ongoing support 
to the lead facilitator, and a network of facilitators developed in the same way that the Schwartz Round model is provided and supported.

\section{DESIGN INSIGHT}

There is growing recognition of the importance of drawing on patient experiences and stories to improve care, but how this is done to achieve the best results for both the patients involved and the services delivered is still being debated. Patient and public involvement and engagement has become central to quality improvement and service redesign. Ensuring engagement of those involved in both delivering and receiving healthcare is essential in ensuring the acceptability of interventions, with co-design offering one such approach. The importance of supporting processes to ensure authentic and meaningful involvement shouldn't be underestimated. We have embedded the use of the 4Pi framework in our quality improvement work in Northwest London, which has provided a guiding framework for involvement. This has been specifically used in the co-design of a tool to facilitate discussion and support shareddecision making. ${ }^{1}$ But it's also important to note that often this work goes under-recognised, and often the efforts and commitments of staff, patients, and the public goes unseen. This type of work, and contributors' efforts, are highlighted only in exceptional cases, and where resources have been made available for involvement.

SIMW seems to offer a useful and practical approach to engaging and involving both staff and patients in the improvement journey. This also reflects the need for a person-centered approach, as outlined by McCormack, ${ }^{2}$ which recognises the need to engage with all those involved in healthcare. SIMW, also helps reposition the role and value of experience within healthcare, which goes beyond simple anecdote, and draws on real-life firsthand experience that is both contextualised and relevant within the organisation.

\section{Stuart Green}

Public Health Research Fellow

NIHR CLAHRC Northwest London

School of Public Health

Imperial College London

London, United Kingdom

\section{References:}

1. Green SA, Evans L, Matthews R. et al. Service user engagement in quality improvement: applying the national involvement standards. The Journal of Mental Health Training, Education and Practice. 2016;11(5):279-85.

2. McCormack B, McCance TV. Development of a framework for person-centred nursing. Journal of Advanced Nursing. 2006;56(5): 472-9.

\section{REFERENCES}

1. Bolster D, Manias E. Person-centred interactions between nurses and patients during medication activities in an acute hospital setting: Qualitative observation and interview study. International Journal of Nursing Studies. 2010;47(2):154-65.

2. MacKean GL, Thurston WE, Scott CM. Bridging the divide between families and health professionals' perspectives on family-centred care. Health Expectations. 2005;8(1):74-85.

3. Mid Staffordshire NHS Foundation Trust. Report of the Mid Staffordshire NHS Foundation Trust Public InquiryExecutive Summary. London: Crown Copyright; 2013.

4. Royal United Hospitals Bath: NHS Foundation Trust. See it my way: Feedback from 'Living with a long-term health condition event. Patient and Carer Experience Report: Q4 January-March 2018: p. 12.

5. Royal United Hospitals Bath: NHS Foundation Trust. "See it my way: Feedback from 'Losing a loved one' event. Patient and Carer Experience Report: Q1 April-June 2018: p. 14. 


\section{ACKNOWLEDGEMENTS}

The author would like to thank all patients, carers, and staff who have participated in See it my way and whose stories have been recorded. Audio recordings and films of SIMW events are available to all RUH staff on the hospital intranet. While the author cannot ensure the public has full consent/permission to view all these films at the time of publication, people are welcome to contact the author for further information (see Corresponding Author section for email). A video segment of David Watson, a patient who spoke about his experience of Alzheimer's and of being in hospitalat See it my way-living with dementia (held 11 October 2017) is available here: https://vimeo.com/244732072/5ac1e7ee83

\section{PEER REVIEW}

Not commissioned. Externally peer reviewed.

\section{CONFLICTS OF INTEREST}

The authors declare that they have no competing interests.

\section{FUNDING}

None

\section{ETHICS COMMITTEE APPROVAL}

None 